\title{
Expression of the receptor for advanced glycation end-products and frequency of polymorphism in lung cancer
}

\author{
HONGMEI WANG ${ }^{1,2}$, YONGCHUN $\mathrm{LI}^{3}$, WENCHENG YU ${ }^{1}$, LIQING MA ${ }^{3}, \mathrm{XIA} \mathrm{JI}^{3}$ and WEI XIAO ${ }^{2}$ \\ ${ }^{1}$ Department of Respiratory Medicine, The Affiliated Hospital of Qingdao University, Qingdao, \\ Shandong 266003; ${ }^{2}$ Department of Respiratory Medicine, Qilu Hospital, Shandong University, \\ Jinan, Shandong 250012; ${ }^{3}$ Asthma Laboratory, Qingdao Key Laboratory of Common Disease, \\ Qingdao Municipal Hospital, Qingdao, Shandong 266071, P.R. China
}

Received May 19, 2014; Accepted February 27, 2015

DOI: $10.3892 / \mathrm{ol} .2015 .3200$

\begin{abstract}
Receptor for advanced glycation end products (RAGE) is associated with the pathogenesis of cancer progression. The pathological effects mediated through RAGE are physiologically inhibited by soluble RAGE (sRAGE). The aim of the present study was to identify the expression of the sRAGE, RAGE and RAGE ligands in serum samples and lung cancer tissue obtained from lung cancer patients. Using ELISA and immunohistochemistry, it was observed that the sRAGE levels were downregulated in the serum, the expression of RAGE was decreased in the lung cancer tissue and the RAGE ligands HMGB1 and S100 were upregulated in cancer tissue. Furthermore, the presence of several selected types of RAGE polymorphism that occur in lung cancers were measured in the tissue samples. An association between the $-429 \mathrm{~T} / \mathrm{C}$ and $2184 \mathrm{~A} / \mathrm{G}$ polymorphisms of RAGE and the genesis and progression of lung cancer was identified. The comparison between various histological subtypes and stages of lung cancer was performed with the aim to clarify the biological role of the RAGE gene, and identify a biomarker to aid diagnosis and predict the prognosis for lung cancer patients.
\end{abstract}

\section{Introduction}

It is well-known that lung cancer is the leading cause of cancer-associated mortality worldwide. In 2011, 221,000 novel cases of lung and bronchial cancer were diagnosed, and $\sim 156,900$ mortalities occurred due to lung cancer in the USA. The five-year survival rate of all lung cancer patients subsequent to diagnosis is only $\sim 15.6 \%$. Delayed diagnosis is a fundamental obstacle in improving lung cancer

Correspondence to: Dr Hongmei Wang, Department of Respiratory Medicine, The Affiliated Hospital of Qingdao University, 16 Jiangsu Road, Qingdao, Shandong 266003, P.R. China E-mail: dor.whm@163.com

Key words: RAGE, soluble RAGE, lung cancer, RAGE polymorphism outcomes (1). A number of studies have focused on the molecular and cellular changes that occur during the initiation and progression of lung cancer. However, the gene polymorphisms involved, which are closely associated with the tumorigenesis and invasion of lung cancer, remain unclear (2-4). Therefore, it is essential to investigate effective lung cancer biomarkers at the early stages of disease and identify novel targets for the treatment of the disease.

The receptor for advanced glycation end products (RAGE) is a multi-ligand transmembrane receptor that belongs to the immunoglobulin superfamily. The extracellular domain of RAGE is termed soluble RAGE (sRAGE) and acts as an endogenous inhibitor of RAGE by binding circulating ligands and inhibiting RAGE-induced cellular signaling, tissue damage and dysfunction (5). RAGE is a pattern-recognition receptor that binds a variety of ligands, including the S100/calgranulin family, high mobility group box-1 (HMGB-1), cluster of differentiation (CD) $11 \mathrm{~b}$, amyloid- $\alpha$ peptide and $\beta$-sheet fibrils. RAGE is involved in several pathological processes, including those in diabetes, Alzheimer's disease and systemic amyloidosis (5).

In contrast to healthy adult tissues in the body, in which RAGE and sRAGE are expressed at a low level, the expression levels of endogenous RAGE and sRAGE have been reported to be high in normal adult lung tissue (6). However, the expression of RAGE and sRAGE has been identified as downregulated in non-small cell lung carcinoma (NSCLC) (7) and idiopathic pulmonary fibrosis (8). This reveals that RAGE is involved in lung pathogenesis.

Previous studies have indicated that RAGE expression is also closely associated with the invasive and metastatic activity of cancer, including gastric (9) and colon cancer (10). Upregulation of RAGE has been identified in breast (11), colon and pancreatic cancers (12), but downregulation of the expression of RAGE and sRAGE has been reported in lung and esophageal cancer $(12,13)$.

Studies investigating RAGE polymorphism have demonstrated that the genetic background of RAGE is associated with NSCLC $(14,15)$. Schenk et al identified six novel sequence variants of RAGE in primary NSCLC lesions compared with the corresponding normal tissues, but no somatic tumor-associated mutations were identified in the sequence analysis (14). Therefore, additional investigation of the expression of RAGE and 
polymorphism of the RAGE gene in various stages of lung cancer is required.

In the present study, the expression levels of sRAGE, RAGE and the HMGB1 and S100 RAGE ligands were measured in serum and tissue obtained from patients with small cell lung cancer (SCLC) and NSCLC. The presence of several types of RAGE polymorphism was assessed in these lung cancer tissue samples, and the current study aimed to identify the association between various types of RAGE gene polymorphism and lung cancer. Furthermore, a comparison was made between RAGE expression and the presence of polymorphisms and variables comprising gender variance and various histological subtypes and stages of lung cancer. The aim of the present study was to identify aspects of the biological role of the RAGE gene and to determine a biomarker for the diagnosis of lung cancer and evaluation of the prognosis of a patient.

\section{Patients and methods}

Patients and samples. Lung cancer patients and healthy volunteers were recruited from Qingdao Municipal Hospital and The Affiliated Hospital of Qingdao University Medical School (Qingdao, Shandong, China), between January 2010 and December 2012. All subjects were aged between 30 and 75 years old and did not possess a current diagnosis of high blood pressure, diabetes mellitus, liver or kidney dysfunction, or Alzheimer's disease (AD). Venous blood samples were collected from patients by venipuncture subsequent to a 12-h fasting period, and the samples were drawn into sterile vacutainers (Hunan Liuyang Medical Instrument Factory, Liuyang, China) that either contained $1 \%$ heparin as an anticoagulant for blood cell isolation or lacked anticoagulant for serum isolation. The lung tissue specimens used for immunohistochemical (IHC) staining were collected from tumor and paired non-tumor tissues obtained from a target number of $\geq 20$ patients diagnosed with each type of lung cancer at various stages. The tissues were excised during pulmonary resection. In total, $5 \mathrm{ml}$ of venous blood was also collected from each patient during a lung biopsy procedure for the measurement of sRAGE expression.

For the polymorphism study, 275 lung cancer patients and 126 healthy volunteers were recruited in total. The lung cancer patients comprised 113 patients with adenocarcinoma, 99 patients with squamous cell carcinoma and 63 patients with small cell carcinoma (Table I). The patients diagnosed with adenocarcinoma and squamous cell carcinoma were grouped according to the guidelines for tumor-node-metastasis (TNM) stages I-IV, based on the size of the primary tumor, lymphatic nodal involvement and distance between the metastasis and primary tumor (16). Patients possessing tumors classified as stage I, II or IIIA were classified as early/middle stage, while patients possessing tumors classified as stages IIIB and IV were classified as late stage lesions.

The present study was conducted in accordance with the Declaration of Helsinki (17), and was performed with approval from the Ethics Committee of the Affiliated Hospital of Qingdao University. Written informed consent was obtained from all participants.
Cytokine measurement. To obtain serum samples, the blood samples were left undisturbed to clot at room temperature for 15-30 $\mathrm{min}$. The clot was removed by centrifugation at $1,000-2,000 \times \mathrm{g}$ for $10 \mathrm{~min}$, at $4^{\circ} \mathrm{C}$. The serum was separated and stored at $-80^{\circ} \mathrm{C}$ for subsequent testing of cytokine production. sRAGE production was assayed using an ELISA kit (R\&D Systems, Minneapolis, MN, USA) according to the manufacturer's instructions.

IHC analysis. Lung tissue specimens were obtained from resected tumor tissues and adjacent non-tumor tissues excised during the pulmonary resection procedure. The lung tissues were fixed in $4 \%$ formalin, embedded in paraffin, sliced and placed on slides prior to staining. The slides were deparaffinized with xylene and graded ethanol solutions. All slides were quenched in hydrogen peroxide, blocked with $10 \%$ normal rabbit serum and digested with proteinase $\mathrm{K}$. The slides were stained with polyclonal rabbit anti-human RAGE (cat. no. ab65965), monoclonal mouse anti-pig HMGB1 (cat. no. ab11354) or monoclonal mouse anti-human S100 A (cat. no. ab52272) antibodies, which were purchased from Abcam (Cambridge, MA, USA) and then detected using the Universal Vectastain Elite ABC kit, anti-mouse IgG/rabbit IgG kit (cat. no. PK-6200; Vector Laboratories, Burlingame, CA, USA). Five images were captured from each slide using an Olympus IX50 inverted microscope (original magnification, x100; Olympus, Tokyo, Japan). The slides were quantified by histogram analysis using Adobe Photoshop CS (Adobe Systems, Mountain View, CA, USA), as previously described $(18,19)$. The data were expressed as the percentage of positive cells per high-power field (HP) in 10 images and were expressed as the mean \pm standard error of the mean (SEM).

RAGE polymorphism analysis. Blood was collected from donors and DNA was isolated using a Genomic DNA Isolation kit (Jiamei Biotech Co., Ltd.) for whole blood according to the manufacturer's instructions. Four polymorphisms of the RAGE gene, comprising -429 T/C, -374 T/A, Gly82Ser and $2184 \mathrm{~A} / \mathrm{G}$, were tested using polymerase chain reaction (PCR) and the restriction digestion method $(20,21)$. Enzyme digestion products were separated on $3 \%$ agarose gels. The PCR primer sequences, annealing temperatures, size of PCR fragments, restriction enzymes and expected size of the fragments from various genotypes of RAGE polymorphism are listed in Table II.

Statistical analysis. The results are expressed as the mean \pm SEM. The number of independent donors in each experiment is indicated in the figure legend. Statistical analysis of IHC staining and cytokine analysis was performed by independent sample $t$-tests, which were conducted using SPSS software, version 17 (SPSS, Chicago, IL, USA). For the analysis of the polymorphisms of RAGE, the incidence of the wild-type, minor homozygous and heterozygous alleles were expressed as a percentage of the total number of patient samples analyzed. Differences between the allelic and genotypic frequencies observed in the control group and those identified in lung cancer patients were assessed for significance using Fisher's exact test or $\chi^{2}$ test. $\mathrm{P} \leq 0.05$ was 
Table I. Clinical characteristics of lung cancer patients compared with healthy control individuals.

\begin{tabular}{|c|c|c|}
\hline \multirow{2}{*}{$\begin{array}{l}\text { Patient } \\
\text { characteristics }\end{array}$} & \multicolumn{2}{|c|}{ Group, n (\%) } \\
\hline & Lung cancer & Healthy control \\
\hline Total, n (\%) & $275(100.00)$ & $126(100.00)$ \\
\hline Male & $170(61.82)$ & $84(66.67)$ \\
\hline Female & $105(38.18)$ & $42(33.33)$ \\
\hline Age, years \pm SD & $59.8 \pm 10.4$ & $57.1 \pm 11.2$ \\
\hline \multicolumn{3}{|c|}{ Adenocarcinoma, n (\%) } \\
\hline Total & $113(100.00)$ & \\
\hline \multicolumn{3}{|l|}{ Stage } \\
\hline Early/middle & 47 (41.59) & \\
\hline Late & $66(58.41)$ & \\
\hline \multicolumn{3}{|l|}{ Gender } \\
\hline Male & $59(52.21)$ & \\
\hline Female & $54(47.79)$ & \\
\hline \multicolumn{3}{|l|}{$\begin{array}{l}\text { Squamous cell } \\
\text { carcinoma, n }(\%)\end{array}$} \\
\hline Total & $99(100.00)$ & \\
\hline \multicolumn{3}{|l|}{ Stage } \\
\hline Early/middle & $48(48.48)$ & \\
\hline Late & $51(51.52)$ & \\
\hline \multicolumn{3}{|l|}{ Gender } \\
\hline Male & $70(70.71)$ & \\
\hline Female & $29(29.29)$ & \\
\hline \multicolumn{3}{|l|}{$\begin{array}{l}\text { Small cell } \\
\text { carcinoma, } \mathrm{n}(\%)\end{array}$} \\
\hline Total & $63(100.00)$ & \\
\hline Male & $41(65.08)$ & \\
\hline Female & $22(34.92)$ & \\
\hline
\end{tabular}

SD, standard deviation.

considered to indicate a statistically significant difference. Statistical analysis was performed using the StatView software (Apple, Inc., Cupertino, CA, USA).

\section{Results}

Clinical characteristics of the patients with lung cancer. The clinical characteristics of the lung cancer patients enrolled for the assessment of polymorphisms, including the age, gender and smoking history, were obtained from medical records and are presented in Table I. For the assessment of polymorphisms, age-matched lung cancer patients $(59.8 \pm 10.4$ years old $)$ and control donors $(57.1 \pm 11.2$ years old $)$ were recruited. The percentage of males and females was also maintained between the lung cancer and control groups. The lung cancer patients consisted of 170 male and 105 female patients. Overall, $51.2 \%$ of male patients with lung cancer were cigarette smokers and $28.6 \%$ of female patients were cigarette smokers. By contrast, in the healthy control group, the percentage of smokers was decreased compared with the lung cancer group, as $27.4 \%$ of males were smokers and $16.7 \%$ of females were smokers. The present study defined smokers as active smokers and patients that had completely discontinued smoking for $<15$ years. The incidence of passive smoking was not considered.

Lung cancer patients were classified based on the clinical pathological diagnosis and allocated to the adenocarcinoma, squamous cell carcinoma, including adenosquamous cell carcinoma, and small cell carcinoma groups. Patients with adenocarcinoma and squamous cell carcinoma were sub-classified into the early/middle and late stages of disease, as aforementioned. Out of the 113 adenocarcinoma patients, $39.8 \%$ of patients demonstrated early/middle-stage and $60.2 \%$ demonstrated late-stage disease. Out of the 99 patients with squamous cell carcinoma, $48.3 \%$ of patients demonstrated early/middle-stage and $51.7 \%$ demonstrated late-stage disease.

Serum SRAGE level decreased in all tested lung cancer patients. It has been reported that the serum sRAGE level can be used as a predictive biomarker for diabetes (22), sepsis (23) and acute lung injury (24). Therefore, the sRAGE level in the serum of lung cancer patients was examined using ELISA. The data revealed that the serum sRAGE level was significantly decreased in adenocarcinoma $(485.6 \pm 73.1 \mathrm{pg} / \mathrm{ml})$, squamous cell carcinoma $(424.5 \pm 55.2 \mathrm{pg} / \mathrm{ml})$ and small cell carcinoma patients $(318.9 \pm 25.9 \mathrm{pg} / \mathrm{ml})$ compared with the healthy control group $(697.6 \pm 83.2 \mathrm{pg} / \mathrm{ml})$ (Fig. 1A). However, detailed analysis did not reveal a stage-dependent change in serum sRAGE level, as no significant change between late stage cancer and early/middle stage cancer patients was identified (Fig. 1B). Notably, a significant decrease in the sRAGE level was identified in the serum of smokers $(338.9 \pm 22.9 \mathrm{pg} / \mathrm{ml})$ compared with non-smokers $(623.4 \pm 92 \mathrm{pg} / \mathrm{ml})$ in the lung cancer group (Fig. 1C). Furthermore, a comparison was made between the expression of sRAGE in male $(339.4 \pm 36.3 \mathrm{pg} / \mathrm{ml})$ and female patients $(564.6 \pm 89.1 \mathrm{pg} / \mathrm{ml})$, and it was revealed that male patients possessed a decreased sRAGE level compared with female patients (Fig. 1D). This may possibly be due to $51.2 \%$ of male patients being smokers, while only $28.6 \%$ of female patients were smokers.

Expression of RAGE decreased in lung cancer tissues, while the expression of the RAGE ligands increased. Since the serum level of sRAGE was reduced significantly in all lung cancer patients, RAGE expression was then examined in the lung tissue samples using an IHC method. As expected, RAGE expression was markedly decreased in adenocarcinoma $(\mathrm{P}<0.05)$ and squamous cell carcinoma tissue samples $(\mathrm{P}<0.05)$ compared with the non-cancerous tissue obtained from the same patient (Fig. 2A-D). However, there was no significant difference in RAGE expression between adenocarcinoma and squamous cell carcinoma tissues (Fig. 2A, B and D), which indicates that the downregulation of RAGE expression is not dependent on lung cancer types. This finding was consistent with Bartling's finding that RAGE expression was reduced in lung cancer patients at the mRNA and protein level (7). 
Table II. Polymerase chain reaction conditions and expected products for various polymorphisms of the RAGE gene.

\begin{tabular}{|c|c|c|c|c|c|}
\hline Polymorphism & Primer squence & $\begin{array}{c}\mathrm{Tm} \\
{ }^{\circ} \mathrm{C}\end{array}$ & $\begin{array}{l}\text { Product } \\
\text { length, bp }\end{array}$ & Enzyme & $\begin{array}{l}\text { Expected band } \\
\quad \text { size, bp }\end{array}$ \\
\hline Gly82Ser & $\begin{array}{l}\text { F, 5'-GTAAGCGGGGCTCCTGTTGCA-3' } \\
\text { R, 5'-GGCCAAGGCTGGGGTTGAAGG-3' }\end{array}$ & 63.0 & 397 & $A l u \mathrm{I}$ & $\begin{array}{l}\mathrm{GG}^{\text {a }}: 248,149 \\
\mathrm{SS}^{\text {b: }} 181,67,149 \\
\mathrm{GS}^{\text {b }}: 248,149,181,67\end{array}$ \\
\hline$-374 \mathrm{~T} / \mathrm{A}$ & $\begin{array}{l}\text { F, 5'-GGGGCAGTTCTCTCCTCACT-3' } \\
\text { R, 5'-GGTTCAGGCCAGACTGTTGT-3' }\end{array}$ & 59.5 & 250 & $\begin{array}{c}M f e \mathrm{I} \\
(M u n \mathrm{I})\end{array}$ & $\begin{array}{l}\mathrm{TT}^{\mathrm{a}}: 215,35 \\
\mathrm{AA}^{\mathrm{b}}: 250 \\
\mathrm{TA}^{\text {b: }}: 250,215,35\end{array}$ \\
\hline$-429 \mathrm{~T} / \mathrm{C}$ & $\begin{array}{l}\text { F, 5'-GGGGCAGTTCTCTCCTCACT-3' } \\
\text { R, 5'-GGTTCAGGCCAGACTGTTGT-3' }\end{array}$ & 59.5 & 250 & AluI & $\begin{array}{l}\mathrm{TT}^{\mathrm{a}}: 250 \\
\mathrm{CC}^{\mathrm{b}}: 162,88 \\
\mathrm{TC}^{\mathrm{b}}: 250,162,188\end{array}$ \\
\hline $2184 \mathrm{~A} / \mathrm{G}$ & $\begin{array}{l}\text { F, 5'-GGGGCAGTTCTCTCCTCACT-3' } \\
\text { R, 5'-GGTTCAGGCCAGACTGTTGT-3' }\end{array}$ & 59.5 & 402 & $B f a \mathrm{I}$ & $\begin{array}{l}\mathrm{AA}^{\mathrm{a}}: 266,136 \\
\mathrm{GG}^{\mathrm{b}}: 174,92,136 \\
\mathrm{AG}^{\mathrm{b}}: 266,136,174,92\end{array}$ \\
\hline
\end{tabular}

${ }^{\text {a}}$ Wild type allele. ${ }^{\mathrm{b}}$ Mutant allele. Tm, annealing temperature.
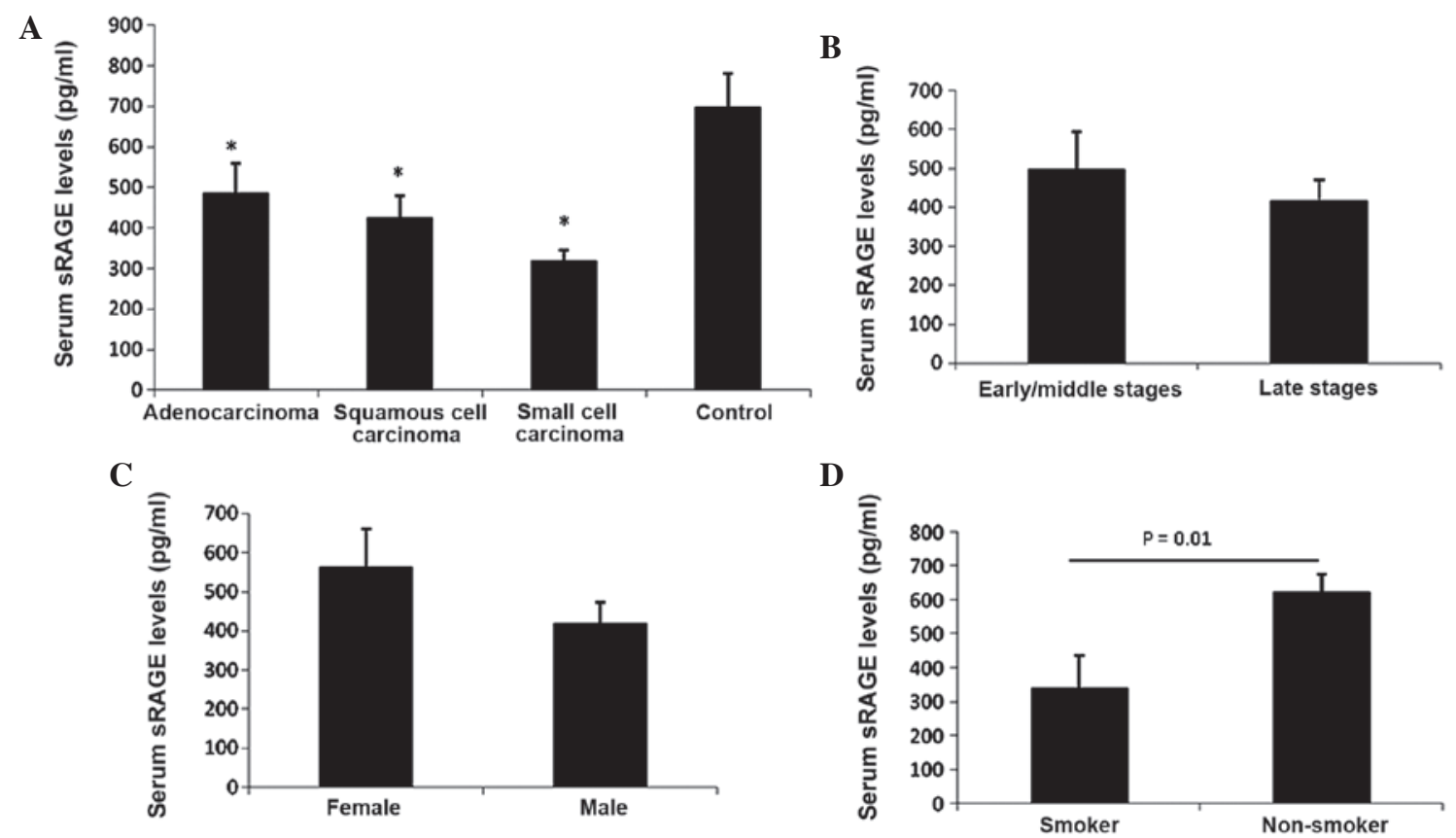

Figure 1. The level of sRAGE in the serum obtained from lung cancer patients was significantly reduced compared with the serum obtained from the healthy control individuals. sRAGE production in the serum samples was measured by ELISA. (A) Serum sRAGE levels in the serum obtained from lung cancer patients compared with the level in the serum of healthy donors. (B) Comparison between the sRAGE level of early/middle stage cancer patients and late stage cancer patients. (C) Comparison between the sRAGE level in smoker and non-smoker lung cancer patients. (D) Comparison between the sRAGE level in female and male lung cancer patients. All experiments were performed in duplicate. "P<0.05 vs. control.

Subsequently, the expression of the RAGE ligands HMGB-1 and S100 was examined in lung cancer tissues and the presence of a correlation between the expression of RAGE and the ligands was assessed. As expected, the expression of S100 (Fig. 2G) and HMGB-1 (Fig. 2G) in normal lung tissue was revealed to be extremely low and almost undetectable. However, in adenocarcinoma (Fig. 2E and I) and squamous cell carcinoma (Fig. $2 \mathrm{~F}$ and $\mathrm{G}$ ) tissues, the expression of S100 and HMGB-1 was markedly upregulated and there was a significant difference between the expression of the two RAGE ligands in cancerous and normal lung tissue samples (Fig. 2H and L).

Gly82Ser and -374T/A RAGE polymorphisms were not associated with lung cancer, but the $-429 T / C$ and $2184 A / G R A G E$ polymorphisms were associated with lung cancer. In the present study, the occurrence of four different types of RAGE gene polymorphisms was assessed in lung cancer patients and healthy control individuals, with the investigated polymorphisms consisting of Gly82Ser, -374T/A, -429T/C and 
Table III. Frequency of the alleles of the Gly82Ser polymorphism of the RAGE gene in lung cancer patients and healthy controls.

\begin{tabular}{|c|c|c|c|c|c|}
\hline Patient characteristics & $\mathrm{GG}, \%$ & $\mathrm{GS}, \%$ & $\mathrm{SS}, \%$ & $\mathrm{G}, \%$ & $\mathrm{~S}, \%$ \\
\hline Adenocarcinoma & 64.83 & 30.77 & 4.40 & 80.22 & 19.78 \\
\hline Early/middle stage & 52.72 & 41.67 & 5.56 & 73.61 & 26.39 \\
\hline Late stage & 72.72 & 23.64 & 3.64 & 84.55 & 15.45 \\
\hline Squamous cell carcinoma & 78.18 & 20.00 & 1.82 & 88.18 & 11.82 \\
\hline Early/middle stage & 81.48 & 18.52 & 0.00 & 90.74 & 9.26 \\
\hline Late stage & 75.00 & 21.43 & 3.57 & 85.71 & 14.29 \\
\hline Small cell carcinoma & 76.92 & 23.08 & 0.00 & 88.46 & 11.54 \\
\hline Healthy controls & 67.53 & 28.57 & 3.90 & 81.82 & 18.18 \\
\hline
\end{tabular}

No significant differences were identified between the allelic frequencies in the cancer and control groups.

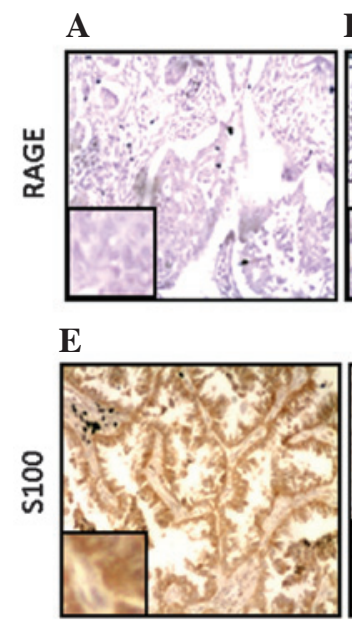

B

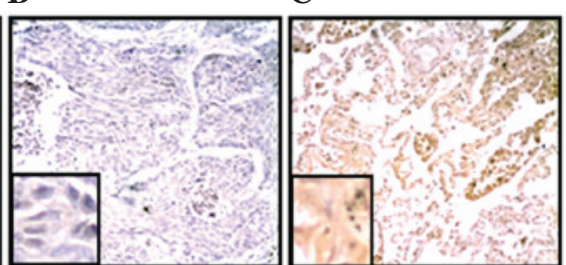

$\mathbf{F}$
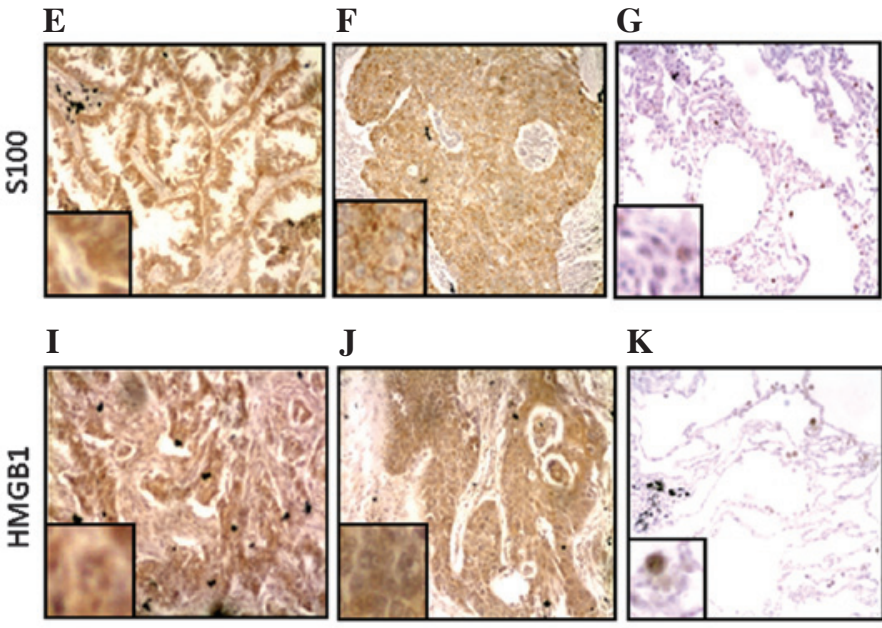

Adenocarcinoma
J

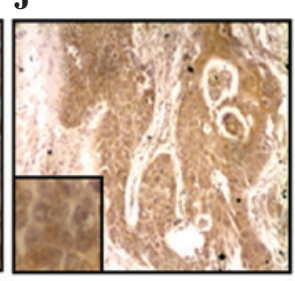

Squamous cell carcinoma
K

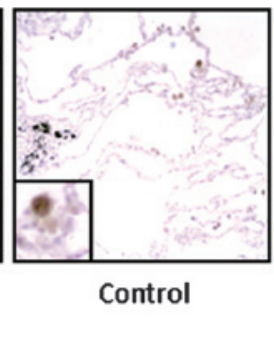

D

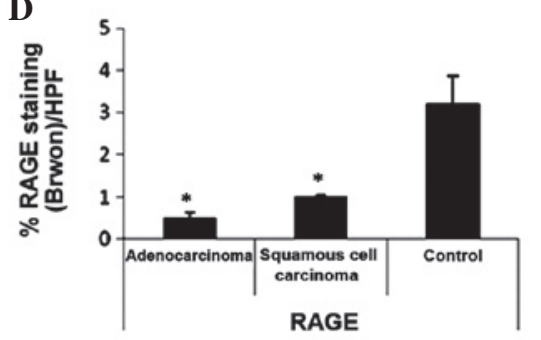

H

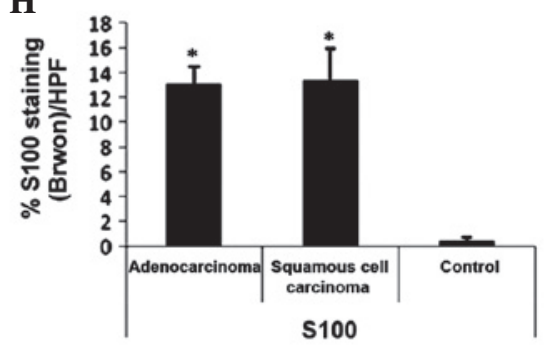

L

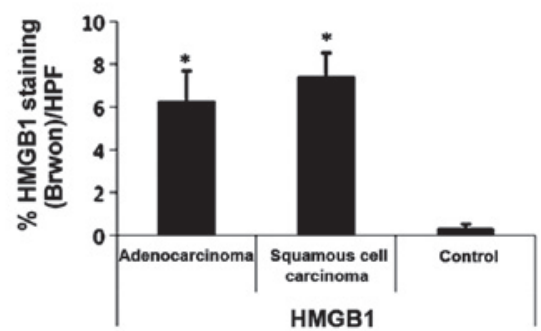

Figure 2. The expression of RAGE and the RAGE ligands S100 and HMGB1 in lung cancer tissue compared with non-cancerous control tissues. The cancerous and non-cancerous lung tissues were obtained from tissue biopsy and subjected to immunohistochemical staining for RAGE. The images were captured using an inverted microscope (original magnification, x100). The tissues consisted of (A, E and I) adenocarcinoma, (B, F and J) squamous cell carcinoma and $(\mathrm{C}, \mathrm{G}$ and $\mathrm{K})$ non-cancer control tissue samples. ( $\mathrm{D}, \mathrm{H}$ and $\mathrm{L}$ ) The images were quantified by histogram analysis using Adobe Photoshop CS. The inset in each picture isan enlarged section of the original image. The images are representative images obtained from $>20$ independent donors for each type of cancer and control tissue. ${ }^{*} \mathrm{P}<0.05$ vs. control.

2184A/G. For each polymorphism, the percentage frequency of the wild-type and minor alleles, homozygous type, and minor and heterozygous alleles of the polymorphisms were calculated for the lung cancer and control groups. The frequency of these alleles in samples obtained from various stages of adenocarcinoma and squamous cell carcinoma were also calculated. Statistical analysis of the differences between the stages of small cell carcinoma was not performed due to the low number of patient samples.
Statistical analysis of the differences between the allelic and genotype frequencies of the Gly82Ser (Table III) and -374T/A (Table IV) polymorphisms of RAGE did not reveal any variation in distribution between the patients with lung cancer and healthy control individuals. Detailed analysis did not reveal any statistical difference in the occurrence of these polymorphisms between the early/middle stage and late stage cancer patients, indicating that the Gly82Ser and -374T/A polymorphisms of the RAGE gene were not associated with 
Table IV. Frequency of the alleles of the -374T/A polymorphisms of the RAGE gene in lung cancer patients and healthy controls.

\begin{tabular}{|c|c|c|c|c|c|}
\hline Patient characteristics & TT, $\%$ & TA, \% & $\mathrm{AA}, \%$ & $\mathrm{~T}, \%$ & A, $\%$ \\
\hline Adenocarcinoma & 71.59 & 23.86 & 4.55 & 83.52 & 16.48 \\
\hline Early/middle stage & 77.14 & 17.14 & 5.71 & 85.71 & 14.29 \\
\hline Late stage & 67.92 & 28.30 & 3.77 & 82.08 & 17.92 \\
\hline Squamous cell carcinoma & 63.79 & 31.03 & 5.17 & 79.31 & 20.69 \\
\hline Early/middle stage & 60.71 & 35.71 & 3.57 & 78.57 & 21.43 \\
\hline Late stage & 65.52 & 27.59 & 6.90 & 79.31 & 20.69 \\
\hline Small cell carcinoma & 53.85 & 38.46 & 7.69 & 73.08 & 26.92 \\
\hline Healthy controls & 72.73 & 24.68 & 2.60 & 85.06 & 14.94 \\
\hline
\end{tabular}

No significant differences were identified between the allelic frequencies in the cancer and control groups.

Table V. Frequency of the alleles of the $-429 \mathrm{~T} / \mathrm{C}$ polymorphisms of the RAGE gene in lung cancer patients and healthy controls.

\begin{tabular}{|c|c|c|c|c|c|}
\hline Patient characteristics & $\mathrm{TT}, \%$ & $\mathrm{TC}, \%$ & $\mathrm{CC}, \%$ & $\mathrm{~T}, \%$ & $\mathrm{C}, \%$ \\
\hline Adenocarcinoma & 70.97 & 27.96 & 1.08 & 84.95 & 15.05 \\
\hline Early/middle stage ${ }^{a}$ & 89.47 & 10.53 & 0.00 & 94.74 & 5.26 \\
\hline Late stage & 57.14 & 41.07 & 1.79 & 77.68 & 22.32 \\
\hline Squamous cell carcinoma ${ }^{\mathrm{b}}$ & 62.71 & 33.90 & 3.39 & 79.66 & 20.34 \\
\hline Early/middle stage ${ }^{c}$ & 78.57 & 21.43 & 0.00 & 89.29 & 10.71 \\
\hline Late stage & 48.39 & 45.16 & 6.45 & 70.97 & 29.03 \\
\hline Small cell carcinoma & 84.62 & 15.38 & 0.00 & 92.31 & 7.69 \\
\hline Healthy controls & 79.22 & 20.78 & 0.00 & 89.61 & 10.39 \\
\hline
\end{tabular}

${ }^{\mathrm{a}} \mathrm{P}=0.001$ vs. late stage; ${ }^{\mathrm{b}} \mathrm{P}=0.047$ vs. control; ${ }^{\mathrm{c}} \mathrm{P}=0.05$ vs. late stage.

lung cancers in the present study. Additionally, the Gly82Ser and -374T/A polymorphisms were not associated with the stage of lung cancer.

In the case of the $-429 \mathrm{~T} / \mathrm{C}$ polymorphism (Table V), the present results revealed that out of the patients with squamous cell carcinoma, $79.66 \%$ possessed the T-allele, $20.34 \%$ possessed the $\mathrm{C}$-allele, $62.71 \%$ possessed the TT allele and $3.39 \%$ possessed the CC allele. In the control group, $89.61 \%$ possessed the T-allele, $15.05 \%$ possessed the C-allele, $79.22 \%$ possessed the TT allele and $0 \%$ possessed the $\mathrm{CC}$ allele. The frequency of the TT genotype and T allele was significant lower in patients with squamous cell carcinoma compared with the healthy control group $(\mathrm{P}=0.047)$. A detailed analysis of patients with squamous cell carcinoma at various stages revealed that there was no significant difference between the occurrence of polymorphism in the early/middle stage and that in the healthy controls. However, there was a notable increase in the incidence of polymorphism in the late stage of squamous cell carcinoma, where the $\mathrm{T}$ - and $\mathrm{C}$-alleles were present in 70.97 and $29.03 \%$ of patients, respectively, and the TT, TC and CC variants were present in $48.39,45.16$ and $6.45 \%$ of patients, respectively, which was a significant increase compared with the healthy controls $(\mathrm{P}=0.05)$. In the patients with adenocarcinoma, no significant difference in the occurrence of the $-479 \mathrm{~T} / \mathrm{C}$ polymorphism was observed between the lung cancer patients and healthy controls, but the patients with late-stage adenocarcinoma demonstrated a significantly decreased genotypic frequency of the wild-type TT allele (57.14\%) and increased genotypic frequency of the minor type CC allele (41.07\%) compared with patients in the early/middle stage of disease, who demonstrated an incidence of 89.47 and $10.53 \%$ for the TT and CC alleles, respectively $(\mathrm{P}=0.001)$.

Notably, the most significant association between the RAGE polymorphism and lung cancer was in the occurrence of the $2184 \mathrm{~A} / \mathrm{G}$ polymorphism (Table VI). In the healthy control population, only the wild-type A allele was identified, but analysis of all three types of lung cancer revealed the appearance of the minor G-allele. The G-allele was present in $6.98 \%$ of adenocarcinoma patients, $6.12 \%$ of squamous cell carcinoma patients and $7.69 \%$ of small cell carcinoma patients. The present data revealed a statistical difference between the occurrence of this allele in all cancer groups and the healthy control group $(\mathrm{P}<0.05)$. Additionally, no patients were identified as homozygous for the minor GG allele in the present study. In the comparisons of genotypic frequencies between various stages of lung cancer, it was found that the AG variant was present in $13.95 \%$ of adenocarcinoma patients, while the AG variant was present in $3.23 \%$ of early/middle stage patients and $20.37 \%$ in late stage patients, demonstrating a significant increase between the two groups $(\mathrm{P}=0.048)$. The AG variant 
Table VI. Frequency of the alleles of the $2184 \mathrm{~A} / \mathrm{G}$ polymorphism of the RAGE gene in lung cancer patients and healthy controls.

\begin{tabular}{|c|c|c|c|c|c|}
\hline Patient characteristics & $\mathrm{AA}, \%$ & $\mathrm{AG}, \%$ & $\mathrm{GG}, \%$ & $\mathrm{~A}, \%$ & $\mathrm{G}, \%$ \\
\hline Adenocarcinoma $^{a}$ & 86.05 & 13.95 & 0.00 & 93.02 & 6.98 \\
\hline Early/middle stage ${ }^{b}$ & 96.77 & 3.23 & 0.00 & 98.39 & 1.61 \\
\hline Late stage & 79.63 & 20.37 & 0.00 & 89.81 & 10.19 \\
\hline Squamous cell carcinomac & 87.76 & 12.24 & 0.00 & 93.88 & 6.12 \\
\hline Early/middle stage & 92.00 & 8.00 & 0.00 & 96.00 & 4.00 \\
\hline Late stage & 83.33 & 16.67 & 0.00 & 91.67 & 8.33 \\
\hline Small cell carcinoma $^{d}$ & 84.62 & 15.38 & 0.00 & 92.31 & 7.69 \\
\hline Healthy controls & 100.00 & 0.00 & 0.00 & 100.00 & 0.00 \\
\hline
\end{tabular}

${ }^{a} \mathrm{P}=0.02968$ vs. control; ${ }^{\mathrm{b}} \mathrm{P}=0.048$ vs. late stage; ${ }^{\mathrm{c}} \mathrm{P}=0.00149$ vs. control; ${ }^{\mathrm{d}} \mathrm{P}=0.0069$ vs. control.

Table VII. Frequency of the alleles of the Gly82Ser polymorphism of the RAGE gene in male and female lung cancer patients.

\begin{tabular}{|c|c|c|c|c|c|}
\hline Gender & $\mathrm{GG}, \%$ & $\mathrm{GS}, \%$ & $\mathrm{SS}, \%$ & $\mathrm{G}, \%$ & $\mathrm{~S}, \%$ \\
\hline Adenocarcinoma & 66.32 & 29.47 & 4.21 & 81.05 & 18.95 \\
\hline Male & 63.83 & 34.04 & 2.13 & 80.85 & 19.15 \\
\hline Female & 66.67 & 27.08 & 6.25 & 80.21 & 19.79 \\
\hline Squamous cell carcinoma & 78.57 & 19.64 & 1.79 & 88.39 & 11.61 \\
\hline Male & 78.85 & 19.23 & 1.92 & 88.46 & 11.54 \\
\hline Female & 75.00 & 25.00 & 0.00 & 87.50 & 12.50 \\
\hline Small cell carcinoma & 76.92 & 23.08 & 0.00 & 88.46 & 11.54 \\
\hline Male & 77.78 & 22.22 & 0.00 & 88.89 & 11.11 \\
\hline Female & 75.00 & 25.00 & 0.00 & 87.50 & 12.50 \\
\hline
\end{tabular}

No significant differences were identified between the allelic frequencies in male and female patients.

was present in $12.24 \%$ of squamous cell carcinoma patients, and the genotypic frequency of $\mathrm{AG}$ increased between the early/middle stage incidence of $8 \%$ and the late stage incidence of $16.67 \%(\mathrm{P}=0.05)$. In small cell carcinoma patients, the AG variant was determined to be present in $15.38 \%$ of patients. Overall, the $2184 \mathrm{~A} / \mathrm{G}$ polymorphism was the only RAGE polymorphism in the present study that demonstrated the ability to distinguish between the small cell carcinoma patients and the healthy control individuals.

Incidence of the $-429 T / C$ and $2184 A / G$ polymorphisms of RAGE was significantly different between male and female lung cancer patients. Subsequent to the allelic frequency of the four types of polymorphism of the RAGE gene being elucidated in patients with adenocarcinoma, squamous cell carcinoma and small cell carcinoma, a clarification of whether gender played a role in RAGE gene polymorphism in various cancers was attempted. Table VII reports the allelic frequency of the Gly82Ser polymorphism of the RAGE gene in male and female lung cancer patients, which did not demonstrate any statistically significant difference between the genders in all three types of cancer. Similarly, no difference was observed in the incidence of the -374T/A polymorphism between males and females with adenocarcinoma or squamous cell carcinoma (Table VIII). However, a significant change was observed in the incidence of the $-374 \mathrm{~T} / \mathrm{A}$ polymorphism between males and females with small cell carcinoma $(\mathrm{P}<0.05)$, as $100 \%$ of female patients expressed the heterozygous TA allele, while in male patients, $50 \%$ expressed the TT allele, $30 \%$ expressed the TA allele and $20 \%$ expressed the AA allele. In female patients, $50 \%$ were identified as possessing the $\mathrm{T}$ allele and $50 \%$ possessed the A allele, while in male patients, $65 \%$ possessed the $\mathrm{T}$ allele and $35 \%$ possessed the A allele.

Notably, the 429T/C (Table IX) and 2184A/G (Table X) polymorphisms exhibited a significant difference between the distribution of the polymorphisms in male and female patients in all three types of lung cancer $(\mathrm{P}<0.05)$. It was observed that in adenocarcinoma, the male patients demonstrated a decreased frequency of the wild-type TT allele of the $-429 \mathrm{~T} / \mathrm{C}$ polymorphism $(61.70 \%)$ and a decreased incidence of the wild-type AA allele of the $2184 \mathrm{~A} / \mathrm{G}$ polymorphism $(81.40 \%)$ compared with the female patients $(80.43$ and $90.70 \%$, respectively). In small cell carcinoma, male patients possessed an increased frequency of the wild-type TT allele of the -429T/C polymorphism $(100.00 \%)$ and an increased frequency of the wild-type AA allele of the $2184 \mathrm{~A} / \mathrm{G}$ polymorphism $(100.00 \%)$ compared with the female patients $(50.00$ and $50.00 \%$, respectively). By contrast, in squamous cell carcinoma, the 
Table VIII. Frequency of the alleles of the -374T/A polymorphism of the RAGE gene in male and female lung cancer patients.

\begin{tabular}{|c|c|c|c|c|c|}
\hline Gender & $\mathrm{TT}, \%$ & TA, $\%$ & $\mathrm{AA}, \%$ & $\mathrm{~T}, \%$ & $\mathrm{~A}, \%$ \\
\hline Adenocarcinoma & 23.86 & 71.59 & 4.55 & 59.66 & 40.34 \\
\hline Male & 22.73 & 70.45 & 6.82 & 57.95 & 42.05 \\
\hline Female & 25.00 & 72.73 & 2.27 & 61.36 & 38.64 \\
\hline Squamous cell carcinoma & 31.03 & 63.79 & 5.17 & 62.93 & 37.07 \\
\hline Male & 32.08 & 64.15 & 3.77 & 64.15 & 35.85 \\
\hline Female & 25.00 & 75.00 & 0.00 & 62.50 & 37.50 \\
\hline Small cell carcinoma & 38.46 & 53.85 & 7.69 & 65.38 & 34.62 \\
\hline Male $^{\mathrm{a}}$ & 50.00 & 30.00 & 20.00 & 65.00 & 35.00 \\
\hline Female & 0.00 & 100.00 & 0.00 & 50.00 & 50.00 \\
\hline
\end{tabular}

${ }^{\mathrm{a}} \mathrm{P}<0.05$ vs. female patients.

Table IX. Frequency of the alleles of the $-429 \mathrm{~T} / \mathrm{C}$ polymorphism of the RAGE gene in male and female lung cancer patients.

\begin{tabular}{|c|c|c|c|c|c|}
\hline Gender & $\mathrm{TT}, \%$ & $\mathrm{TC}, \%$ & $\mathrm{CC}, \%$ & $\mathrm{~T}, \%$ & $\mathrm{C}, \%$ \\
\hline Adenocarcinoma & 70.97 & 27.96 & 1.08 & 86.00 & 14.00 \\
\hline Male $^{\mathrm{a}}$ & 61.70 & 36.17 & 2.13 & 90.50 & 9.50 \\
\hline Female & 80.43 & 19.57 & 0.00 & 95.50 & 4.50 \\
\hline Squamous cell carcinoma & 62.71 & 33.90 & 3.39 & 88.00 & 12.00 \\
\hline Male $^{\mathrm{a}}$ & 63.16 & 33.33 & 3.51 & 88.50 & 11.50 \\
\hline Female & 50.00 & 50.00 & 0.00 & 99.50 & 0.50 \\
\hline Small cell carcinoma & 84.62 & 15.38 & 0.00 & 99.00 & 1.00 \\
\hline Male $^{\mathrm{a}}$ & 100.00 & 0.00 & 0.00 & 100.00 & 0.00 \\
\hline Female & 50.00 & 50.00 & 0.00 & 99.00 & 1.00 \\
\hline
\end{tabular}

${ }^{\mathrm{a}} \mathrm{P}<0.05$ vs. female patients.

Table X. Frequency of the alleles of the $2184 \mathrm{~A} / \mathrm{G}$ polymorphism of the RAGE gene among male and female lung cancer patients.

\begin{tabular}{|c|c|c|c|c|c|}
\hline Gender & $\mathrm{AA}, \%$ & $\mathrm{AG}, \%$ & $\mathrm{GG}, \%$ & $\mathrm{~A}, \%$ & $\mathrm{G}, \%$ \\
\hline Adenocarcinoma & 86.05 & 13.95 & 0.00 & 93.02 & 6.98 \\
\hline Male $^{\mathrm{a}}$ & 81.40 & 18.60 & 0.00 & 90.70 & 9.30 \\
\hline Female & 90.70 & 9.30 & 0.00 & 95.35 & 4.65 \\
\hline Squamous cell carcinoma & 87.76 & 12.24 & 0.00 & 93.88 & 6.12 \\
\hline Male $^{\mathrm{a}}$ & 81.25 & 18.75 & 0.00 & 90.63 & 9.38 \\
\hline Female & 100.00 & 0.00 & 0.00 & 100.00 & 0.00 \\
\hline Small cell carcinoma & 84.62 & 15.38 & 0.00 & 92.31 & 7.69 \\
\hline Male $^{\mathrm{a}}$ & 100.00 & 0.00 & 0.00 & 100.00 & 0.00 \\
\hline Female & 50.00 & 50.00 & 0.00 & 75.00 & 25.00 \\
\hline
\end{tabular}

${ }^{\mathrm{a}} \mathrm{P}<0.05$ vs. female patients.

male patients demonstrated an increased frequency of the wild-type TT allele of the $-429 \mathrm{~T} / \mathrm{C}$ polymorphism $(63.16 \%)$ and a decreased frequency of the wild-type AA allele of the $2184 \mathrm{~A} / \mathrm{G}$ polymorphism $(81.25 \%)$ compared with the female patients (50.00 and $100.00 \%$, respectively).

\section{Discussion}

Gene profiling in tissues derived from lung carcinomas has previously revealed large numbers of differentially expressed genes in these tissues compared with the histologically normal 
tissues obtained from the same individual or tissue obtained from healthy individuals (25). In the present study, it was demonstrated that the multi-ligand receptor RAGE was one of the genes that is differentially expressed in lung cancer patients. Initially, the serum sRAGE level was found to be decreased in NSCLC and SCLC patients. Subsequently, it was demonstrated that the expression of RAGE was decreased in patients with lung cancer while the expression of the RAGE ligands HMGB1 and S100 were increased in lung cancer tissue compared with non-cancerous tissue excised from NSCLC patients. In addition, the occurrence of four types of polymorphism of the RAGE gene, consisting of Gly82Ser, -374T/A, $-429 \mathrm{~T} / \mathrm{C}$ and $2184 \mathrm{~A} / \mathrm{G}$, was measured in the patients with lung cancer and the healthy control individuals. It was demonstrated that the Gly82Ser and -374T/A RAGE polymorphisms were not associated with lung cancer, while the $-429 \mathrm{~T} / \mathrm{C}$ and 2184A/G polymorphisms were associated with lung cancer.

The mechanism behind the association between sRAGE and disease remains controversial. One study has reported that sRAGE was elevated in patients with sepsis and was associated with patient outcome (23). Another study demonstrated that the sRAGE level was elevated during acute lung injury or acute respiratory distress syndrome, regardless of the presence or absence of severe sepsis (26). It has also been revealed that the level of serum sRAGE was elevated in breast cancer patients (27), and the elevated serum sRAGE levels were reported to be associated with an increased risk of cardiovascular disease in Japanese patients with type 2 diabetes (28). In the present study, it was revealed that the serum sRAGE level was significantly decreased in NSCLC and SCLC patients compared with healthy controls. In addition, a notable decrease in the level of serum sRAGE was identified in smokers compared with non-smokers. It is well-known that cigarette smoking is a major cause of lung cancer, and the decrease in the expression of sRAGE in lung cancer patients and smokers provides a simple supportive tool for predicting the development of lung cancer. Therefore, the serum sRAGE level may be used as potential biomarker for the occurrence of lung cancer.

The biological function of RAGE and its ligands in cancer also remain unclear. Increased RAGE activation has been observed in a variety of pathological disorders. In certain cancers, the expression of RAGE and its ligands is highly upregulated and in others the expression is downregulated. For example, in pancreatic and prostate cancer, enhanced expression of RAGE and HMGB1 were found to be associated with metastases (12). In colon cancer, joint expression of RAGE and HMGB1 was found to lead to enhanced migration in the cancer cell line, and the level of expression of RAGE and HMGB1 increased with the stage of cancer (12). By contrast, in lung cancer, a higher tumor stage was reported to be characterized by a downregulation in RAGE expression at the mRNA and protein levels (7). The present study confirmed that the expression of RAGE was downregulated in lung cancer tissue compared with noncancerous tissue from the same patient. The downregulation of sRAGE and RAGE was found to not be dependent on the type or stage of lung cancer. Investigation of the RAGE binding ligands revealed the upregulation of the RAGE ligands S100 and HMGB1 in cancer tissues. It is possible that in normal tissues, RAGE binds and leads to the degradation of the ligands, but in lung cancer tissue the downregulation of RAGE results in more ligands being present in the tissue.

It has been revealed that $\mathrm{S} 100$ calcium binding protein $\mathrm{P}$ (S100P) was expressed at greater levels in colon cancer compared with matched normal tissue, and S100P has also been demonstrated to stimulate colon cancer cell growth and migration, extracellular signal-regulated kinase phosphorylation, and nuclear factor- $\kappa \mathrm{B}$ activation in vitro. However, in contrast to the expression in lung cancers, RAGE was also upregulated in colon cancer tissues (10). As a result, it was challenging to apply the simple ligand/receptor binding and degradation theory as an explanation for the phenomena of RAGE expression. Notably, RAGE is a receptor that is capable of binding multiple ligands in all cell types, and thus RAGE and the RAGE ligands HMGB1 and S100 are able to affect each other. These ligands also bind other receptors in addition to RAGE. Thus, RAGE and the HMGB1 and S100 ligands are able to function independently of each other.

In the present study, the incidence of four types of RAGE gene polymorphism was assessed. It was revealed that the Gly82Ser and -374T/A RAGE polymorphisms were not associated with lung cancer, while the $-429 \mathrm{~T} / \mathrm{C}$ polymorphism was associated with squamous cell carcinoma and the $2184 \mathrm{~A} / \mathrm{G}$ RAGE polymorphism was associated with all three types of lung cancer. Notably, the healthy control individuals demonstrated an increased incidence of the wild-type TT allele of the $-429 \mathrm{~T} / \mathrm{C}$ polymorphism and all individuals possessed the wild-type AA allele of the $2184 \mathrm{~A} / \mathrm{G}$ polymorphism. Patients in a late stage of disease demonstrated a reduced frequency of the wild-type allele and an increased frequency of the minor allele. Consistent with the present results, a study investigating RAGE polymorphism and breast cancer performed by Tesarová et al found no difference in the incidence of the -374T/A polymorphism between breast cancer patients and healthy controls (13). It was reported that the $-374 \mathrm{~T} / \mathrm{A}$ polymorphism demonstrated no effect on the sRAGE level. However, it was also observed that the serum sRAGE level was higher in patients that possessed the wild-type TT variant instead of the $-429 \mathrm{~T} / \mathrm{C}$ polymorphism, wild-type GG variant instead of the Gly82/Ser polymorphism, and wild-type AA variant instead of the $2184 \mathrm{~A} / \mathrm{G}$ polymorphism compared with patients that possessed the minor allele (13). However, a study by Wang et al revealed that the presence of the homozygous minor-type SS variant at the location of the Gly82Ser polymorphism resulted in a lower response to chemotherapy and a poorer clinical outcome in the advanced stages of NSCLC (15).

Notably, the $-429 \mathrm{~T} / \mathrm{C}$ polymorphism of RAGE was associated with squamous cell carcinoma and the $2184 \mathrm{~A} / \mathrm{G}$ polymorphism was associated with the development of NSCLC and SCLC. These variations in genotype cannot be used to explain the common transcriptional downregulation of RAGE in lung cancer patients, as not all lung cancer patients possessed the minor allele of the RAGE gene.

In summary, the present findings reveal that the expression of RAGE was reduced in tissues from human lung cancer patients, and that the polymorphisms of RAGE, in particular the $-429 \mathrm{~T} / \mathrm{C}$ and $2184 \mathrm{~A} / \mathrm{G}$ polymorphisms, were associated with the genesis and progression of lung cancer. The levels of serum 
sRAGE and tissue RAGE may serve as an effective and convenient diagnostic biomarker for lung cancer, and the presence of RAGE polymorphism may aid the diagnosis of lung cancer and the clinical assessment of prognosis.

\section{Acknowledgements}

The authors would like to thank Haiyan Wang, the technician of the Asthma Laboratory (Qingdao Key Laboratory of Common Disease, Qingdao Municipal Hospital) for her skillful technical expertise.

\section{References}

1. Jemal A, Bray F, Center MM, Ferlay J, Ward E and Forman D: Global cancer statistics. CA Cancer J Clin 61: 69-90, 2011.

2. Pulford DJ, Falls JG, Killian JK and Jirtle RL: Polymorphisms, genomic imprinting and cancer susceptibility. Mutat Res 436 : 59-67, 1999.

3. Galvani E, Peters GJ and Giovannetti E: EGF receptor-targeted therapy in non-small-cell lung cancer: role of germline polymorphisms in outcome and toxicity. Future Oncol 8: 1015-1029, 2012

4. Habbous S, Pang V, Eng L, et al: p53 Arg72Pro polymorphism, HPV status and initiation, progression and development of cervical cancer: a systematic review and meta-analysis. Clin Cancer Res 18: 6407-6415, 2012.

5. Herold K, Moser B, Chen Y, Zeng S, Yan SF, Ramasamy R, Emond J, Clynes R and Schmidt AM: Receptor for advanced glycation end products (RAGE) in a dash to the rescue: Inflammatory signals gone awry in the primal response to stress. J Leukoc Biol 82: 204-212, 2007.

6. Brett J, Schmidt AM, Yan SD, et al: Survey of the distribution of a newly characterized receptor for advanced glycation end products in tissues. Am J Pathol 143: 1699-1712, 1993.

7. Bartling B, Hofmann HS, Weigle B, Silber RE and Simm A Down-regulation of the receptor for advanced glycation end-products (RAGE) supports non-small cell lung carcinoma. Carcinogenesis 26: 293-301, 2005.

8. Englert JM, Hanford LE, Kaminski N, et al: A role for the receptor for advanced glycation end products in idiopathic pulmonary fibrosis. Am J Pathol 172: 583-591, 2008.

9. Kuniyasu H, Oue N, Wakikawa A, Shigeishi H, Matsutani N, Kuraoka K, Ito R, Yokozaki $\mathrm{H}$ and Yasui W: Expression of receptors for advanced glycation end-products (RAGE) is closely associated with the invasive and metastatic activity of gastric cancer. J Pathol 196: 163-170, 2002.

10. Fuentes MK, Nigavekar SS, Arumugam T, Logsdon CD, Schmidt AM, Park JC and Huang EH: RAGE activation by S100P in colon cancer stimulates growth, migration, and cell signaling pathways. Dis Colon Rectum 50: 1230-1240, 2007.

11. Hsieh HL, Schäfer BW, Sasaki N and Heizmann CW: Expression analysis of S100 proteins and RAGE in human tumors using tissue microarrays. Biochem Biophys Res Commun 307: 375-381, 2003.

12. Sparvero LJ, Asafu-Adjei D, Kang R, et al: RAGE (Receptor for Advanced Glycation Endproducts), RAGE ligands, and their role in cancer and inflammation. J Transl Med 7: 17, 2009.

13. Tesarová $\mathrm{P}$, Kalousová $\mathrm{M}$, Jáchymová M, Mestek O, Petruzelka L and Zima T: Receptor for advanced glycation end products (RAGE) - soluble form (sRAGE) and gene polymorphisms in patients with breast cancer. Cancer Invest 25 : 720-725, 2007.
14. Schenk S, Schraml P, Bendik I and Ludwig CU: A novel polymorphism in the promoter of the RAGE gene is associated with non-small cell lung cancer. Lung Cancer 32: 7-12, 2001.

15. Wang X, Cui E, Zeng H, Hua F, Wang B, Mao W and Feng X: RAGE genetic polymorphisms are associated with risk, chemotherapy response and prognosis in patients with advanced NSCLC. PLOS ONE 7: e43734, 2012.

16. Mountain CF: A new international staging system for lung cancer. 1986. Chest 136 (Suppl): e25, 2009.

17. World Medical Association: World Medical Association Declaration of Helsinki-Ethical Principles for Medical Research Involving Human Subjects. http://www.wma.net/ en/30publications/10policies/b3/index.html. Accessed March 11, 2015.

18. Lehr HA, Mankoff DA, Corwin D, et al: Anpplication of photoshop-based image analysis to quantification of hormone receptor expression in breast cancer. J Histochem Cytochem 45: 1559-1565, 1997.

19. Wang Y, Wang H, Piper MG, et al: sRAGE induces human monocyte survival and differentiation. J Immunol 185: 1822-1835, 2010.

20. Beránek M, Kanková K, Kolár P and Znojil V: Polymorphisms in the von Willebrand factor gene are not associated with proliferative retinopathy in non-insulin-dependent diabetes mellitus. Ophthalmic Res 34: 327-330, 2002.

21. Kanková K, Márová I, Záhejský J, Muzík J, Stejskalová A, Znojil V and Vácha J: Polymorphisms 1704G/T and 2184A/G in the RAGE gene are associated with antioxidant status. Metabolism 50: 1152-1160, 2001

22. Tam XH, Shiu SW, Leng L, Bucala R, Betteridge DJ and Tan KC: Enhanced expression of receptor for advanced glycation end-products is associated with low circulating soluble isoforms of the receptor in Type 2 diabetes. Clin Sci (Lond) 120: 81-89, 2011.

23. Bopp C, Hofer S, Weitz J, Bierhaus A, Nawroth PP, Martin E, Büchler MW and Weigand MA: sRAGE is elevated in septic patients and associated with patients outcome. J Surg Res 147: 79-83, 2008

24. Liu X, Chen Q, Shi S, Shi Z, Lin R, Tan L, Yu J, Shu Q and Fang X: Plasma sRAGE enables prediction of acute lung injury after cardiac surgery in children. Crit Care 16: R91, 2012.

25. Garber ME, Troyanskaya OG, Schluens K, et al: Diversity of gene expression in adenocarcinoma of the lung. Proc Natl Acad Sci USA 98: 13784-13789, 2001.

26. Jabaudon M, Futier E, Roszyk L, et al: Soluble form of the receptor for advanced glycation end products is a marker of acute lung injury but not of severe sepsis in critically ill patients. Crit Care Med 39: 480-488, 2011.

27. Piperis M, Provatopoulou X, Sagkriotis A, Kalogera E, Ampatzoglou E, Zografos GC, Athanasiou E and Gounaris A: Effect of breast cancer adjuvant therapies on potential biomarkers of pulmonary inflammation. Anticancer Res 32: 4993-5002, 2012.

28. Fujisawa K, Katakami N, Kaneto H, et al: Circulating soluble RAGE as a predictive biomarker of cardiovascular event risk in patients with type 2 diabetes. Atherosclerosis 227: 425-428, 2013. 